\title{
Gradual Green Tax Reforms
}

Carlos de Miguel

Baltasar Manzano 


\title{
GRADUAL GREEN TAX REFORMS*
}

\author{
Carlos de Miguel and Baltasar Manzano* \\ Universidad de Vigo and Economics for Energy •
}

\begin{abstract}
Green tax reforms have become an important tool not only in protecting the environment but also in bringing about a more efficient tax system. However, reforms often imply accepting sacrifices in the short-run and bring about the risk of potential political opposition. Within this framework, the debate on whether to implement green tax reforms in one-step or gradually becomes of great interest. In this paper we use a calibrated dynamic general equilibrium model to evaluate different reforms that consist in increasing energy taxes and adjusting capital taxation in a revenue-neutral framework. Our findings show that, although an environmental dividend is always granted, the efficiency dividend depends on the type of reform, its size and how gradually it is implemented. Thus, one-step reforms that produce an efficiency dividend would imply large efficiency costs in the short-run. In this case, the reform could only produce efficiency gains in the short-run if it is implemented gradually, although such gains would end up disappearing in the long-run.
\end{abstract}

JEL classification: E62, Q43, H23.

Keywords: Green Tax Reform, General Equilibrium.

- Financial support from the Spanish Ministry of Science and Innovation and FEDER (ECO200802752/ECON) and from Xunta de Galicia (10PXIB300177PR) is gratefully acknowledged.

·cmiguel@uvigo.es; bmanzano@uvigo.es.

- Universidad de Vigo. Lagoas-Marcosende s/n. 36200 Vigo (Spain). 


\section{1. - Introduction}

Green tax reforms represent an important advance in the policy struggle against environmental damage caused by modern industrial societies. This is not only due to the fact that these policies are implemented to reduce those damages, but also because they can be used to reassess present tax systems that are often based on taxing factors of production such as labor and capital. Thus, green tax reforms have become instrumental not only in protecting the environment, but also in bringing about a more efficient tax system [see, for example Pearce (1991)]. This makes green tax reforms interesting from an economic as well as an environmental point of view.

From a theoretical perspective, a green tax reform is often associated to the Double Dividend idea [see, Oates (1991) and Bovenberg and De Mooij (1994)], that is, the hypothesis that such a reform would entail not only environmental welfare gains (through pollution reduction), but also economic welfare gains (through efficiency reallocation). Environmental taxes are often less distorting than, for example, capital taxes. Thus, green tax reforms could improve welfare by enhancing the economic efficiency of the tax system and the environment.

In practice, green tax reforms have been of great interest in Europe. As early on as 1996, the European Environmental Agency pointed out how introducing environmental tax reforms could achieve a multiple dividend. Yet introducing environmental taxes (particularly energy taxes) may give way to many political barriers. One of the main points addressed to overcome these barriers is the gradual implementation of environmental tax reforms. In a technical report on market-based instruments for environmental policy, released in 2005, the European Environmental Agency analyzes insights into the main lessons learned from the environmental tax reform experience. One of these insights is the need for a gradual phasing-in of the reforms to generate public support. The same message emerges from Bassi, Brink and Pallemaerts (2009) when analyzing the feasibility of implementing an environmental tax reform.

Although a green tax reform may render economic and environmental benefits, there are many barriers when attempting to implement it. This kind of reform often 
implies accepting short-run sacrifices to achieve long-run environmental quality, but it also raises the risk of political opposition. Within this framework, the debate on whether to implement a green tax reform in one-step or gradually becomes of great interest.

There is extensive literature analyzing the appropriate speed of adjustment of a reform and the main factors behind it [see Nsouli et al. (2002) for a discussion]. The basic idea is to find the optimal adjustment path that maximizes the social welfare subject to a set of structural and financial constraints. The debate between the advocates of a high-speed approach (one-step reform) and those favoring a gradualist approach is based primarily on the weights given to adjustment costs, policy credibility and reform feasibility.

Supporters of the shock approach argue that rapid reforms lead to lower adjustment costs because they increase incentives to relocate resources [see Mussa (1984)]. Under circumstances where product and factor prices adjust immediately and resources can be reallocated without cost, the optimal policy is clear, namely the simultaneous removal of all distortions. Moreover, credibility is an important determinant of the magnitude of the adjustment costs. Thus, if reforms are credible, private agents will align their behavior with the announced policies. In fact, the more credible the reform is, the more quickly it should be implemented. Finally it is difficult to design a detailed sequence of reforms; therefore, reforms should move ahead as rapidly as possible.

Proponents of gradualism point out that, in the real world, resources cannot be reallocated without incurring in costs. A gradual reform could minimize adjustment costs because it generates lower short-term costs and, thus, creates less political opposition. Furthermore, if announced policies and reforms are not credible, agents will be reluctant to respond to the announcement. This could make for a longer adjustment process or could even trigger failure. By contrast, gradualism may enhance credibility if the short-term results are sufficiently favorable. At the same time, proponents of a gradual approach stress that it simply takes time to implement reforms.

Although it would be theoretically optimal to implement a one-step reform in a world without resource reallocation adjustment cost, from a policy-maker point of view, 
the short-run effects could be crucial in deciding whether to implement a policy. When the reform implies short-run sacrifices, implementing it gradually could help mitigate the costs which could be the cause of failure, even if the reform proves to be welfareimproving. Thus, it is interesting to analyze different scenarios of gradualism when implementing environmental policies. This is what our paper aims to do.

We analyze different green tax reforms by using a calibrated dynamic general equilibrium model. We assume increases in taxes on energy used both by households and by firms and adjust capital taxation in a revenue-neutral framework. We focus on the economic implications of gradual versus one-step green tax reforms, for different increases in tax rates, by computing the associated environmental and efficiency dividends.

The results point out that the speed of adjustment in a green tax reform is as crucial in analyzing the economic and environmental impact, as is the size and type of reform. We find that a one-step green tax reform would be better than a gradual reform when considering the complete transitional dynamics path to compute welfare. However, looking only at the short-run effects, a gradual reform makes for initially lower costs, given its smoother adjustment which, in turn, delays the costs of the reform. Then, if we are interested in the immediate impact of the reform, it is possible to find efficiency gains by introducing gradual implementation. When the reform consists in increasing the energy consumption tax, we find an efficiency dividend for a one-step implementation. Yet this efficiency dividend would only emerge after a large number of periods. The same policy gradually implemented induces short-run efficiency gains but at the end it becomes an efficiency cost no matter how gradual the reform may be. Something similar occurs when the reform increases the tax on energy used by firms. There are efficiency gains in the short-run that would later become losses in any kind of gradual policy. In terms of the environment, green tax reforms always induce a dividend but the more gradual the reform is, the lower the welfare gains are.

The paper is organized as follows. In section 2, we specify the model. In section 3 we describe the policy experiments and the calibration of the parameter. Section 4 presents the results and, lastly, in section 5 we summarize the main conclusions. 


\section{2. - The Model}

We set a dynamic general equilibrium model consisting in households, firms and a government that finances an exogenous flow of spending through tax collecting. Energy is used in this economy for consumption (eh) and for production (ef). Prices for both types of energy differ based on the fact that the energy mix of a household and that of a firm are different. We assume energy prices $p^{h}$ and $p^{f}$ to be exogenous.

Firms produce output by a constant return-to-scale technology that combines labor $(n)$, capital $(k)$ and energy $(e f)$. The production function is given by:

$$
F\left(n_{t}, k_{t}, e f_{t}\right)=n_{t}^{\theta}\left[(1-a) k_{t}^{-v}+a e f_{t}^{-v}\right]^{-\frac{1-\theta}{v}}
$$

The representative firm maximizes profits:

$\operatorname{Max}_{n_{t}, k_{t}, e f_{t}} F\left(n_{t}, k_{t}, e f_{t}\right)-w_{t} n_{t}-r_{t} k_{t}-\left(1+\tau_{t}^{f}\right) p^{f} e f_{t}$,

where $w$ and $r$ denote wages and the interest rate, and $\tau^{f}$ is the tax on energy used in production.

First-order conditions for the firm are:

$$
\begin{aligned}
& w_{t}=\frac{\partial F\left(n_{t}, k_{t}, e f_{t}\right)}{\partial n_{t}}, \\
& r_{t}=\frac{\partial F\left(n_{t}, k_{t}, e f_{t}\right)}{\partial k_{t}}, \\
& \left(1+\tau_{t}^{f}\right) p^{f}=\frac{\partial F\left(n_{t}, k_{t}, e f_{t}\right)}{\partial e f_{t}} .
\end{aligned}
$$

The representative household derives utility from:

$$
U\left(A_{t}, n_{t}, H_{t}\right)=\frac{\left[A_{t}^{1-\mu}\left(1-n_{t}\right)^{\mu} H_{t}^{\phi}\right]^{\sigma}}{\sigma},
$$


$A_{t}\left(c_{t}, e h_{t}\right)=\left[(1-\gamma) c_{t}^{\alpha}+\gamma e h_{t}^{\alpha}\right]^{\frac{1}{\alpha}}$

where $A$ is the aggregate good that combines non-energy $(c)$ and energy consumption (eh). The elasticity of substitution between energy and non-energy consumption is 1 / (1$\alpha) . H_{t}$ is a negative externality (pollution) that represents the negative impact on welfare caused by the use of energy ( $e h$ and $e f$ ). We assume $H$ will be given by:

$$
H_{t}=e h_{t}+e f_{t} .
$$

The consumer's problem is to maximize an intertemporal flow of utility subject to the budget constraint:

$$
\begin{aligned}
& \underset{c_{t}, e h_{t}, n_{t}, k_{t+1}}{\operatorname{Max}} \sum_{t=0}^{\infty} \beta^{t} U\left(A_{t}\left(c_{t}, e h_{t}\right), n_{t}, H_{t}\right) \\
& \text { s.t.: } \quad\left(1+\tau_{t}^{c}\right) c_{t}+\left(1+\tau_{t}^{h}\right) p^{h} e h_{t}+k_{t+1}-(1-\delta) k_{t}=\left(1-\tau_{t}^{w}\right) w_{t} n_{t}+\left(1-\tau_{t}^{k}\right) r_{t} k_{t}-T_{t},
\end{aligned}
$$

where $0<\beta<1$ is the discount factor and $\delta$ is the capital depreciation rate. $\tau^{c}, \tau^{h}, \tau^{w}$ and $\tau^{k}$ are respectively the tax rates on the non-energy consumption good, on household consumption of energy, on labor income and on capital income, respectively, and $T$ is a lump-sum tax.

The conditions that solve the consumer's problem are:

$$
\begin{aligned}
& c_{t}: \quad \frac{\partial U\left(A_{t}\left(c_{t}, e h_{t}\right), n_{t}, H_{t}\right)}{\partial A_{t}} \times \frac{\partial A_{t}\left(c_{t}, e h_{t}\right)}{\partial c_{t}}-\lambda_{t}\left(1+\tau_{t}^{c}\right)=0, \\
& e h_{t}: \quad \frac{\partial U\left(A_{t}\left(c_{t}, e h_{t}\right), n_{t}, H_{t}\right)}{\partial U\left(A_{t}\left(c_{t} \partial e h_{t}\right), n_{t}, H_{t}\right)} \times \frac{\partial A_{t}\left(c_{t}, e h_{t}\right)}{\partial n_{t}}+\lambda_{t}\left(1-\lambda_{t}\left(1+\tau_{t}^{h}\right) w_{t}=0,\right. \\
& n_{t}: \quad \frac{p^{h}=0,}{k_{t+1}:} \quad-\lambda_{t}+\beta \lambda_{t+1}\left[1-\delta+\left(1-\tau_{t+1}^{k}\right) r_{t+1}\right]=0 .
\end{aligned}
$$

The government finances an exogenous flow of spending $\left(G_{t}\right)$ by using taxes. Government budget constraint is:

$$
G_{t}=\tau_{t}^{c} c_{t}+\tau_{t}^{h} p^{h} e h_{t}+\tau_{t}^{f} p^{f} e f_{t}+\tau_{t}^{w} w_{t} n_{t}+\tau_{t}^{k} r_{t} k_{t}+T_{t}
$$


The aggregate resources constraint is:

$c_{t}+k_{t+1}-(1-\delta) k_{t}+G_{t}+p^{h} e h_{t}+p^{f} e f_{t}=F\left(n_{t}, k_{t}, e f_{t}\right)$.

A competitive equilibrium for this economy is a set of paths of allocations, prices and policies that satisfy the following conditions:

i) $\left\{c_{t}, e h_{t}, n_{t}, k_{t+1}\right\}$ solve the consumer's problem given prices $\left\{w_{t}, r_{t}, p_{t}^{h}\right\}$ and policies $\left\{\tau_{t}^{c}, \tau_{t}^{h}, \tau_{t}^{w} \tau_{t}^{k}, T_{t}\right\}$.

ii) $\left\{n_{t}, e f_{t}, k_{t}\right\}$ solve the firm's problem given prices $\left\{w_{t}, r_{t}, p_{t}^{f}\right\}$ and the policy $\left\{\boldsymbol{\tau}_{t}^{f}\right\}$.

iii) The government budget constraint holds at each period.

iv) Goods, labor, capital and energy markets clear.

\section{3. - Policy experiments and calibration}

We focus on the welfare changes that emerge from two different green tax reforms. On the one hand an increase in the household energy consumption tax $\left(\tau^{h}\right)$ and, on the other, a reform that raises the tax on energy used by firms $\left(\tau^{f}\right)$. In both cases the government adjusts the capital tax $\left(\tau^{k}\right)$ to balance the budget constraint, keeping constant the other tax rates and, thereby producing revenue-neutral reforms. Although there are consumption and labor taxes in the model, we choose to adjust capital taxes given their strong distortionary welfare effect, as Lucas (1990) and Cooley and Hansen (1992) have shown.

We focus on one-step versus gradual green tax reforms. Thus, the path for the energy tax involved in the reform would be given by:

$$
\begin{aligned}
& \left.\begin{array}{l}
\tau_{t}^{i}=\bar{\tau}^{i} \quad \text { for } t<t^{*} \\
\tau_{t}^{i}=(1-\rho) \ell \%+\rho \tau_{t-1}^{i} \quad \text { for } t \geq t^{*}
\end{array}\right\} \\
& i=h, f, 0 \leq \rho \leq 1, \quad \bar{\tau}^{i}, \ell \dot{k} \text { are respectively pre-reform and post-reform taxes. }
\end{aligned}
$$


Parameter $\rho$ represents the speed of adjustment of the energy tax to its new rate. The larger the value of parameter $\rho$ is, the more gradual the reform would be. For $\rho=0$ we have one-step policy reforms. We focus on the differential impact of one-step versus gradual reforms, computing the welfare changes associated to these policies, by changing the value of parameter $\rho$.

The effect of any of those policies on welfare can be divided into an efficiency dividend and an environmental dividend. The efficiency dividend takes into account changes in aggregate consumption $(A)$ and leisure $(1-n)$ due to the tax reform, keeping the externality $(H)$ constant at the initial level. The environmental dividend will be associated only to changes in the externality, keeping aggregate consumption and leisure constant at the pre-reform level. Bearing in mind the transition between the prereform and the post-reform steady-states, the efficiency and environmental dividends for a time horizon $T$, would be given respectively through the $x_{F}$ and $x_{E}$ variables that solve the following equations:

$$
\begin{aligned}
& \sum_{t=0}^{T} \beta^{t}\left\{U\left(\mathscr{A}_{t}\left(1-x_{F}\right), \cap_{t} \mathrm{H} \bar{H}\right)-U(\bar{A}, \bar{n}, \bar{H})\right\}=0, \\
& \sum_{t=0}^{T} \beta^{t}\left\{U\left(\bar{A}\left(1-x_{E}\right), \bar{n}, H_{t}^{\%}\right)-U(\bar{A}, \bar{n}, \bar{H})\right\}=0,
\end{aligned}
$$

where $\{\bar{A}, \bar{n}, \bar{H}\}$ are the levels of the allocations in the steady state before the tax reform, while $\left\{\mathcal{F}_{t}, A_{t}, H_{t}\right\}$ represent the allocations after the tax reform. Variables $x_{F}$ and $x_{E}$ indicate the percentage reduction in effective aggregate consumption required so that individuals enjoy the same level of pre-tax reform welfare. Hence, $x_{F}, x_{E}>0$ imply that individuals would enjoy more welfare after the tax reform (a welfare dividend), while $x_{F}, x_{E}<0$ represents a welfare cost following the reform. Results are expressed in terms of percentages of GDP.

Welfare changes are usually computed to a time horizon large enough $(T \rightarrow \infty)$ to ensure that the new steady state after the reform is reached. However we also compute the welfare gains for very short time horizons, looking for short-run costs that could prevent the political implementability of those reforms. Thus, we not only focus on the 
welfare effects of green tax reform as a whole, but also look closely at its immediate effects.

The simulation of these policy experiments requires the calibration of the model parameters. Some of the parameters have been chosen so that, in the steady state, the model reproduces some of the most relevant long-run characteristics of the Spanish economy for the period 1978-2005; others take standard values or are obtained from literature. The time period is one year. Table 1 summarizes the parametric values and the different sources used.

Concerning energy parameters, we construct measures of energy prices and energy uses for households and firms following De Miguel and Manzano (2011). Data show that the ratio of household energy consumption to total household consumption is $6.2 \%$ and the ratio of household energy expenditure to total energy expenditure is $52 \%$. The parameters $\{\gamma, a\}$ are chosen to approximate these shares. For the disutility of pollution, we assume an intermediate value, $\phi=-0.5$, throughout the simulations.

\section{4. - Simulation results}

This section presents the results that emerge from the simulation of the two different green tax reforms proposed in section 3. We pay attention to green tax reforms with different speeds of adjustment. The analysis is conducted for the increases of 20, 40, 60 and 80 percentage points in energy tax rate involved in the reform.

According to Figures 1 and 2, in terms of welfare, a one-step policy is always better than a gradual policy both in efficiency and environmental dividends. This result has to do with the lack of adjustment cost for the reallocation of resources. The more gradual the policy is, the lower the welfare dividend is. This is because one-step reforms increase incentives to reallocate resources quickly. Focusing on the size of the tax change we obtain that, for both reforms, the larger the increase in energy taxes is, the worse the efficiency dividend is and the better the environmental dividend is. Moreover, these reforms always imply positive environmental dividends because total energy is 
reduced. The existence of an efficiency dividend, however, depends on the particular reform and the size of the tax increase.

Focusing on the efficiency side, we only find a dividend when the reform moderately raises the tax on household energy consumption (less than a 40 percentage point tax increase) and the reform is not too slow. When we increase the energy used for production, there is always an efficiency welfare cost. The slower the reform is implemented, the larger the efficiency cost is.

From an environmental perspective, increases in any of the energy taxes greatly reduce total consumption of energy, which in turn decreases pollution and improves the environment. The larger the tax increase is, the larger both the energy reduction and the environmental dividend are. When the reform is implemented more gradually, no matter the size of the tax increase, the environmental dividend falls but never becomes a cost.

In order to analyze the impact of a green tax reform, it is crucial to consider the complete transitional dynamics path to compute welfare in as far as it provides information about the total welfare cost/benefit associated to the reform. However, from a policy-maker point of view, implementing the reform would often depend on its shortrun effects. In consequence, a reform with lower short-term costs would face less political opposition.

In the next subsections we analyze the short-run effects of the green tax reforms proposed for tax increases of 20 percentage points and for three different speeds of policy adjustment: a one-step reform $(\rho=0)$, a smooth reform $(\rho=0.5)$ and a very slow reform $(\rho=0.9)$.

\section{1. - Energy consumption tax}

We first address the green tax reform that increases the tax on household energy consumption. The policy has two different and simultaneous effects on the economy. On the one hand households would try to offset the fall in energy consumption caused by the tax increase by raising non-energy consumption. As far as aggregate consumption falls, households would increase leisure and reduce hours worked. On the 
other hand, as the government balances the budget constraint by reducing capital taxes, the price of future consumption relative to present consumption falls, so households would save more by reducing consumption and increasing hours worked. Figure 3 shows that in the first period the balance of those effects would depend on the smoothness of the policy change.

When a one-step reform $(\rho=0)$ is considered, the second effect dominates and the household reacts by reducing energy and non-energy consumption, by increasing savings and by working more. In the next periods, both consumptions recover and hours worked fall until reaching a new steady state with more consumption and more leisure. When we consider the efficiency dividend computed for different time horizons, Table 2 shows that the reform would imply, for a one-period horizon, a large efficiency cost (nearly $1 \%$ of GDP in terms of aggregate consumption) because of the fall in aggregate consumption and leisure. In the subsequent periods, consumption and leisure recover. This improves efficiency and finally obtains a positive dividend for a longer time horizon (more than 40 periods). The result is the opposite on the environmental side. The initial fall in energy consumption implies an environmental dividend that diminishes for as long as energy consumption recovers in next periods.

When the tax reform is assumed to be very slow $(\rho=0.9)$, the first effect dominates, making individuals increase non-energy consumption and leisure to offset the decrease in energy consumption. In this case, individuals would adjust slowly after the reform because the intertemporal incentives are restricted by the increase of the capital tax rate in the first period. In a time horizon of one period the reform would imply an efficiency gain of about 0.2 per cent of GDP in terms of aggregate consumption. This is explained by the increase in aggregate consumption and leisure. Thus a very slow reform would make for efficiency gains in a small time horizon, though these gains would disappear in a few periods. The environmental dividend goes in the opposite direction; it starts with a slow dividend $(0.7 \%)$ that increases as the considered time horizon is raised.

There is an intermediate case $(\rho=0.5)$, in which the first period results in a moderate decrease in non-energy consumption and a small increase in leisure. The reduction in the capital tax rate would be small, making it a poor incentive for the 
households to substitute present and future consumption. In the first period aggregate consumption decreases and leisure increases slightly, thus for a one-period horizon an efficiency cost of nearly $0.4 \%$ of GDP in terms of aggregate consumption emerges. For larger time horizons, over 40 periods, the welfare cost reduces until it becomes an efficiency dividend.

\section{2. - Energy used by firms tax}

In this subsection we implement a green tax reform that consists in an increase in 20 percentage points in the tax on energy used by firms. The long-run results of this reform are dominated by the contractive effects that the tax on the energy input has on the economy, which produces an efficiency cost. However, as can be seen in Table 3, a gradual implementation of this reform can induce an efficiency dividend in the shortrun.

For a one-step reform $(\rho=0)$, Figure 4 shows how households adjust quickly, hence there are no differences depending on the time horizon used to compute welfare changes. In this case, the increase in $\tau^{f}$ induces a large decrease in ef, reducing input productivity and, therefore, capital and labor, and also output and energy and nonenergy consumption. Although the reduction in capital taxes incentivizes investment, the fall in capital productivity reduces the incentive, leaving investment unaltered. Table 3 shows how the increase in leisure cannot offset the large decrease in aggregate consumption, thus the reform induces an efficiency cost of about $0.18 \%$ of GDP in terms of aggregate consumption. There is an environmental dividend driven by the fall in both uses of energy, similar in size for all the time horizons considered.

For a very slow reform $(\rho=0.9)$, the short-run results are quite different from the one-step reform, and an efficiency dividend emerges that remains up to a ten-period time horizon and thereafter becomes a welfare cost. Households reduce investment largely by the fall in capital productivity and the short-run increase in capital tax. The investment reduction allows for an increase in both energy and non-energy consumption that, along with the increase in leisure, induces a positive effect on efficiency in the short-run. This effect is almost 1\% of GDP in terms of aggregate consumption for a 
one-period time horizon. In terms of environmental dividend, this dividend rises with the time horizon because of the smooth adjustment in energy. In the first periods the increase in household energy consumption compensates for the fall in the energy used by firms, but for longer time horizons total energy falls and the environmental dividend increases.

For a smooth policy adjustment $(\rho=0.5)$ there is a mixture between the above cases. Figure 4 shows that variables initially behave in a similar way as in the case of $\rho=0.9$, although the response is smaller in size. The increase in aggregate consumption and leisure in the first period is lower than it is in the case of a very slow reform, thus the efficiency dividend for a one-period horizon falls to under half of the one for $\rho=0.9$. Moreover, the dividend lasts for less than five periods. So the faster the adjustment is, the sooner the negative efficiency effects are noticed. The environmental dividend is larger than that of $\rho=0.9$, and it increases with the time horizon.

\section{5. - Conclusions}

Implementation of a green tax reform can be welfare-improving not only from an environmental perspective, but also from an efficiency point of view. The double dividend hypothesis makes the governments aware that the reforms can be a tool not only in reducing environmental damages, but also in making the tax system more efficient. However, in political terms, as long as large short-run costs emerge, the green tax reform cannot be feasible. Therefore, to measure the welfare dividends/costs of the reform it is just as important to take into account the complete transitional dynamics path as it is to consider a short-run time horizon. Part of these short-run costs could be prevented by introducing gradualism when implementing the policy.

In this paper we simulate a calibrated general equilibrium model by assessing two different reforms, which either increase the tax on household energy consumption or the tax on energy used by firms, by adjusting capital taxation in a revenue-neutral framework. We evaluate the total effects and the short-run effects of the tax reforms on welfare by computing the welfare gain associated to these policies and we explore the implications of implementing a gradual policy in both reforms. 
The results show that the environmental dividend is always granted by the reduction on energy that follows the reforms. The efficiency dividend depends on several factors such as the type of reform, its size and the gradualism of its implementation. We find that the best reform would be a one-step increase of the household energy consumption tax when considering the complete transitional dynamics path to compute welfare. However, we should bear in mind that such a reform would imply large efficiency costs in the short-run, and would subsequently introduce lack of political feasibility for this policy. The reform can only produce efficiency gains in the short-run if it is implemented gradually, although such gains would disappear over a few periods. Focusing on the short-run, we find larger efficiency gains in a gradual increase in the tax on energy used by firms, even though the reform would induce a large efficiency cost in the end.

\section{References}

Bassi, S., P. ten Brink, M. Pallemaerts, and I. von Homeyer (2009). "Feasibility of implementing a radical ETR and its acceptance." In Study of tax reform in Europe over the next decades: implication for the environment for eco-innovation and for household distribution. European Environmental Agency.

Boscá, J. E., J. R. García and D. Taguas (2005). "La fiscalidad en la OCDE: 19652001," Documento de Trabajo D-2005-06. Dirección General de Presupuestos. Ministerio de Economía y Hacienda.

Bovenberg, A. L. and R. A. De Mooij (1994). "Environmental levies and distortionary taxation," American Economic Review 84(4), 1085-1089.

Cooley, T.F. and G.D. Hansen (1992). "Tax distortions in a neoclassical monetary economy," Journal of Economic Theory, 58, 290-316.

De Miguel, C. and B. Manzano (2011). "Green tax reforms and habits". Resource and Energy Economics 33, 231-246.

European Environmental Agency (2005). "Market based instruments in environmental policy in Europe”. EEA Technical Report No 8-2005. 
Goulder, L. H., I. W. H. Parry, R. C. Williams III and D. Burtraw (1999). "The costeffectiveness of alternative instruments for environmental protection in a second-best setting,” Journal of Public Economics 72, 329-360.

Lucas, R.E. Jr. (1990). "Supply-side economics: an analytical review," Oxford Economics Papers, 42(2), 293-316.

Mussa, M. (1984), “The adjustment process and the timing of trade liberalization", NBER Working Paper, No. 1458, National Bureau of Economic Research.

Nsouli, S. M., M. Rached and N. Funke (2005). "The speed of adjustment and the sequencing of economic reforms: Issues and guidelines for policymakers", International Journal of Social Economics, 32(9), 740 - 766.

Oates, W. E. (1991). "Pollution charges as a source of public revenues," Discussion Paper No. OE92-05, Resources for the Future, Washington, DC.

Pearce, D. W. (1991). "The role of carbon taxes in adjusting to global warming," The Economic Journal, 101, 938-948.

Thompson, P. and T. G. Taylor (1995). "The capital-energy substitutability debate: a new look," The Review of Economics and Statistics 77, 565-569. 
Table 1.- Parameter values.

Parameter Value Source

\section{Preferences}

Subjective Discount Factor

$\beta \quad 0.96 \quad$ Standard

Energy Consumption Share

$\gamma \quad 0.036$

Elasticity of Substitution between $1 /(1-\alpha) \quad 0.85$

Goulder et al. (1999)

Energy and non-Energy Consumption

Preference for Leisure

$\begin{array}{lll}\mu & 2 / 3 \quad \text { Standard }\end{array}$

Risk Aversion

$\sigma \quad-1$

Disutility of Pollution

$\phi \quad-0.5$

\section{Technology}

Labor Share

$\begin{array}{ll}\theta & 0.64\end{array}$

Standard

Rate of Depreciation

$\delta \quad 4 \%$

Spanish Data

Elasticity of Substitution between $1 /(1+v) \quad 0.76 \quad$ Thompson and Taylor Capital and Energy

(1995)

\section{Fiscal Parameters}

\begin{tabular}{|c|c|c|c|}
\hline Non-Energy Consumption Tax & $\tau^{c}$ & $7.36 \%$ & $\begin{array}{l}\text { De Miguel and } \\
\text { Manzano (2011) }\end{array}$ \\
\hline Labor Tax & $\tau^{w}$ & $31.52 \%$ & Boscá et al. (2005) \\
\hline Capital Tax & $\tau^{k}$ & $18.41 \%$ & Boscá et al. (2005) \\
\hline Energy Consumption Tax & $\tau^{h}$ & $62.56 \%$ & $\begin{array}{l}\text { De Miguel and } \\
\text { Manzano (2011) }\end{array}$ \\
\hline Energy Used by Firms Tax & $\tau^{f}$ & $24.77 \%$ & $\begin{array}{l}\text { De Miguel and } \\
\text { Manzano (2011) }\end{array}$ \\
\hline Government Spending/GDP & & $16.49 \%$ & Spanish Data \\
\hline
\end{tabular}


Table 2. Energy consumption tax: Efficiency and Environmental dividends in the transitional dynamics for different time horizons (T) and speed of adjustment $(\rho)$.

\begin{tabular}{ccccccc}
\hline & \multicolumn{3}{c}{ Efficiency Dividend } & \multicolumn{3}{c}{ Environmental Dividend } \\
\hline & $\rho=0$ & $\rho=0.5$ & $\rho=0.9$ & $\rho=0$ & $\rho=0.5$ & $\rho=0.9$ \\
\hline $\mathrm{T}=1$ & -0.901 & -0.392 & 0.194 & 4.168 & 2.759 & 0.711 \\
$\mathrm{~T}=2$ & -0.851 & -0.490 & 0.118 & 4.116 & 3.056 & 0.916 \\
$\mathrm{~T}=3$ & -0.804 & -0.542 & 0.053 & 4.067 & 3.239 & 1.097 \\
$\mathrm{~T}=4$ & -0.759 & -0.565 & -0.002 & 4.021 & 3.353 & 1.257 \\
$\mathrm{~T}=5$ & -0.718 & -0.570 & -0.049 & 3.977 & 3.423 & 1.399 \\
$\mathrm{~T}=10$ & -0.542 & -0.499 & -0.190 & 3.793 & 3.506 & 1.903 \\
$\mathrm{~T}=20$ & -0.311 & -0.512 & -0.235 & 3.551 & 3.399 & 2.345 \\
$\mathrm{~T}=30$ & -0.178 & -0.186 & -0.189 & 3.412 & 3.297 & 2.487 \\
$\mathrm{~T}=40$ & -0.100 & -0.109 & -0.136 & 3.329 & 3.230 & 2.534 \\
$\mathrm{~T}=\infty$ & 0.030 & 0.022 & -0.012 & 3.192 & 3.112 & 2.558 \\
\hline
\end{tabular}

These dividends are computed as the values of $x_{F}$ and $x_{E}$ that solve equations (7)-(8) and are expressed as a percentage of GDP in terms of effective aggregate consumption.

Table 3. Energy used by firms' tax: Efficiency and Environmental dividends in the transitional dynamics for different time horizons $(\mathrm{T})$ and speed of adjustment $(\rho)$.

\begin{tabular}{ccccccc}
\hline & \multicolumn{3}{c}{ Efficiency Dividend } & \multicolumn{3}{c}{ Environmental Dividend } \\
\hline & $\rho=0$ & $\rho=0.5$ & $\rho=0.9$ & $\rho=0$ & $\rho=0.5$ & $\rho=0.9$ \\
\hline $\mathrm{T}=1$ & -0.180 & 0.419 & 0.921 & 6.438 & 4.297 & 1.145 \\
$\mathrm{~T}=2$ & -0.180 & 0.240 & 0.787 & 6.439 & 4.819 & 1.510 \\
$\mathrm{~T}=3$ & -0.181 & 0.122 & 0.668 & 6.440 & 5.166 & 1.837 \\
$\mathrm{~T}=4$ & -0.181 & 0.041 & 0.563 & 6.440 & 5.405 & 2.131 \\
$\mathrm{~T}=5$ & -0.182 & -0.016 & 0.470 & 6.441 & 5.577 & 2.395 \\
$\mathrm{~T}=10$ & -0.184 & -0.143 & 0.143 & 6.443 & 5.979 & 3.378 \\
$\mathrm{~T}=20$ & -0.187 & -0.196 & -0.137 & 6.446 & 6.189 & 4.377 \\
$\mathrm{~T}=30$ & -0.188 & -0.204 & -0.223 & 6.447 & 6.251 & 4.811 \\
$\mathrm{~T}=40$ & -0.189 & -0.206 & -0.248 & 6.448 & 6.277 & 5.021 \\
$\mathrm{~T}=\infty$ & -0.191 & -0.206 & -0.252 & 6.450 & 6.312 & 5.303 \\
\hline
\end{tabular}

These dividends are computed as the values of $x_{F}$ and $x_{E}$ that solve equations (7)-(8) and are expressed as a percentage of GDP in terms of effective aggregate consumption. 
Figure 1. Energy consumption tax. Efficiency and environmental dividends with different percentage point (pp) increases in the tax rate.

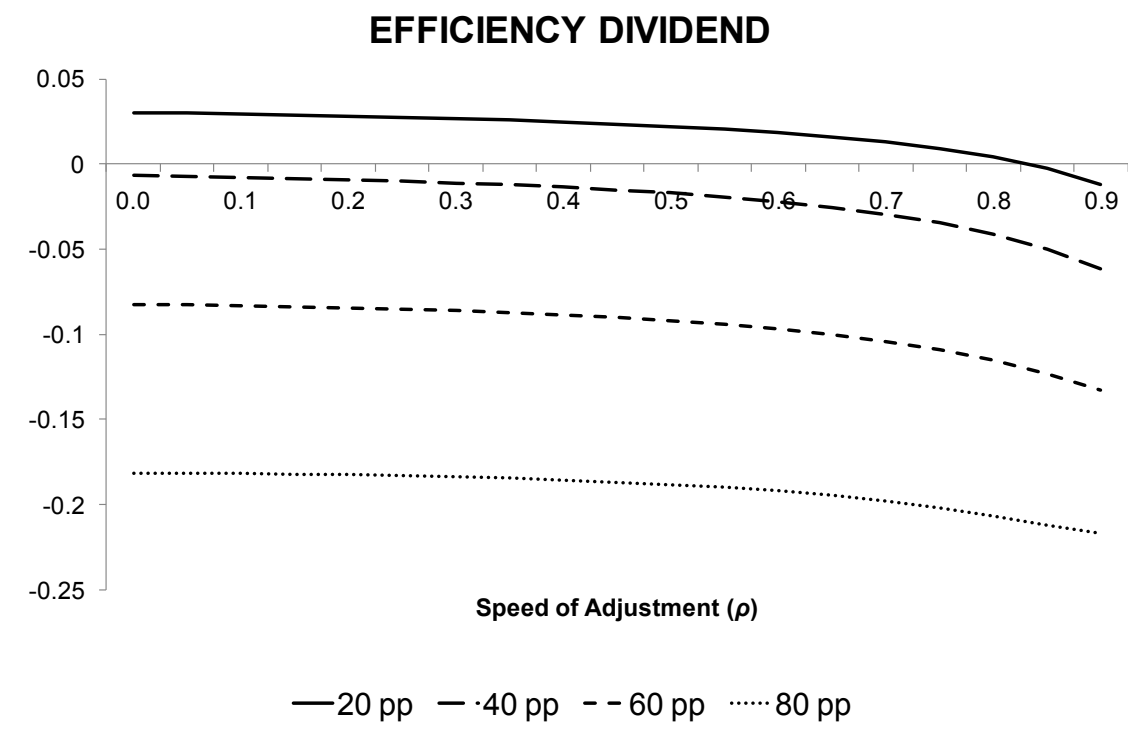

\section{ENVIRONMENTAL DIVIDEND}

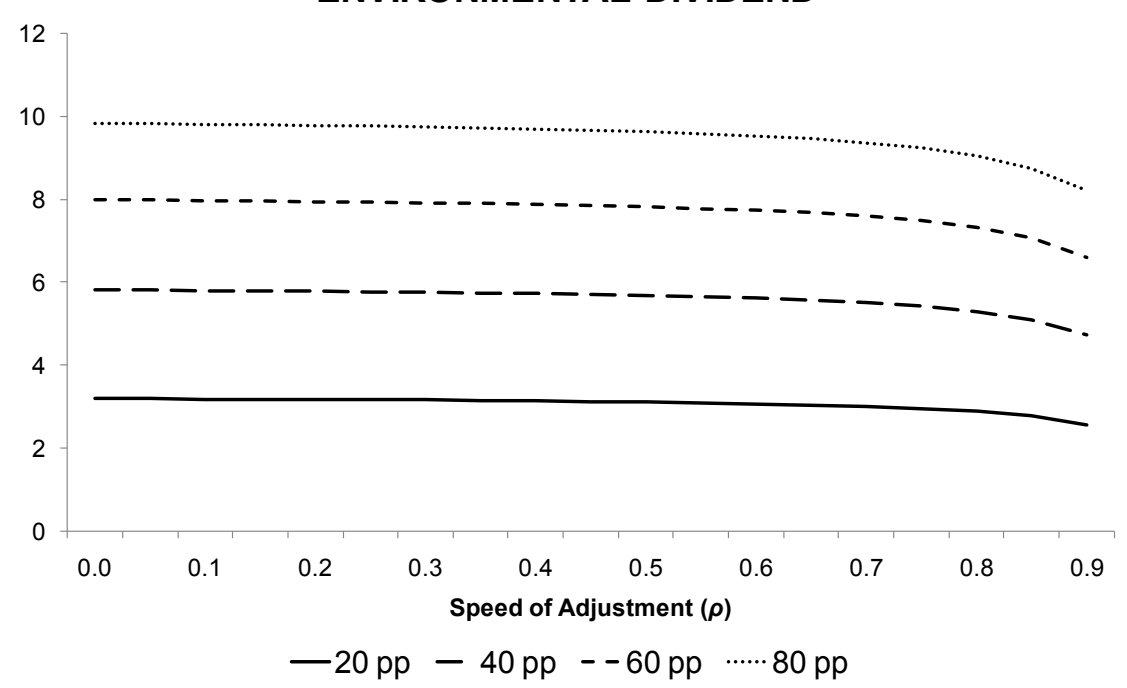


Figure 2. Energy used by firms'. Efficiency and environmental dividends with different percentage point (pp) increases in the tax rate.
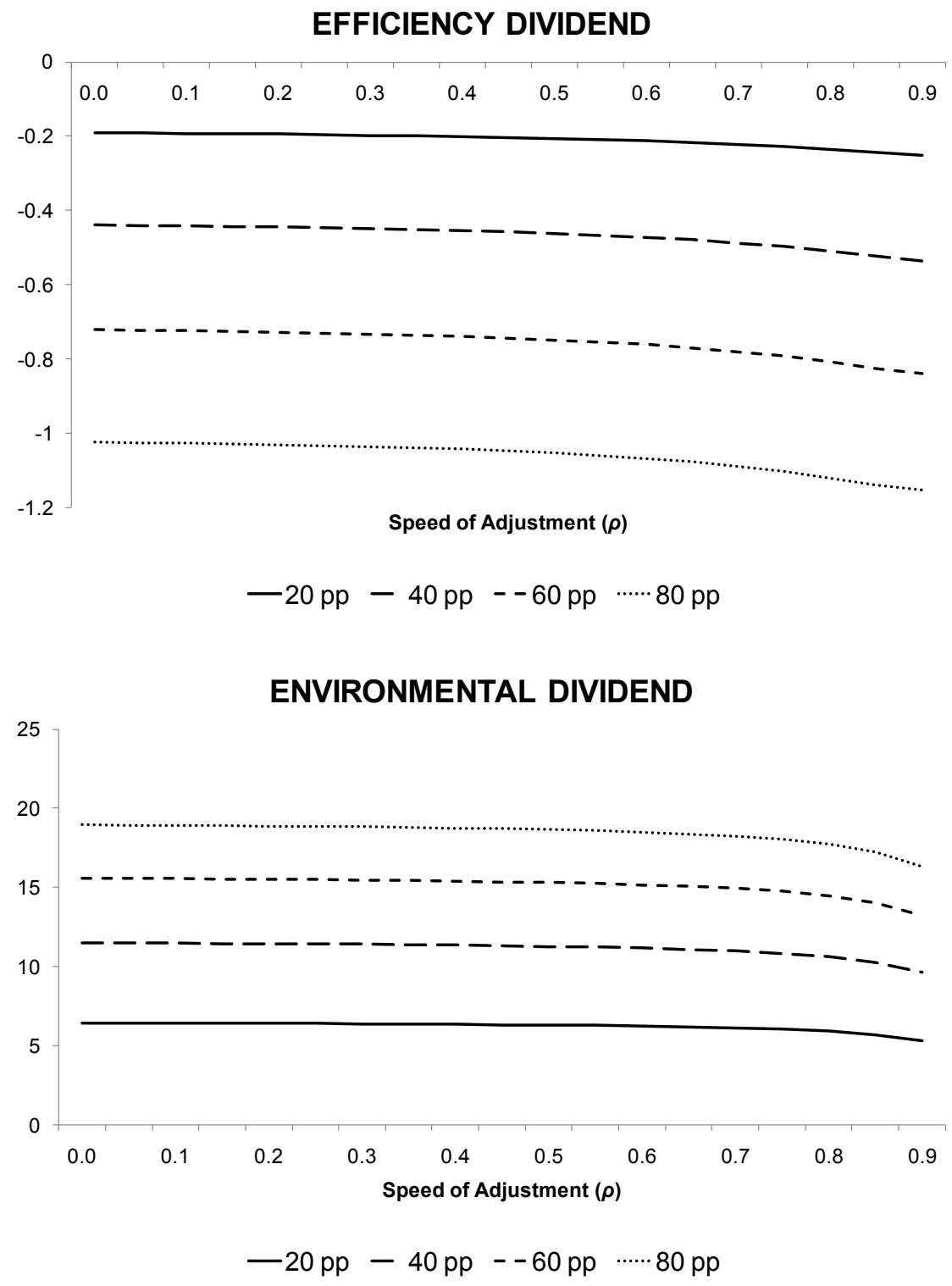
Figure 3.- Energy consumption tax. Deviations from the initial steady state (except taxes). Time period is one year.
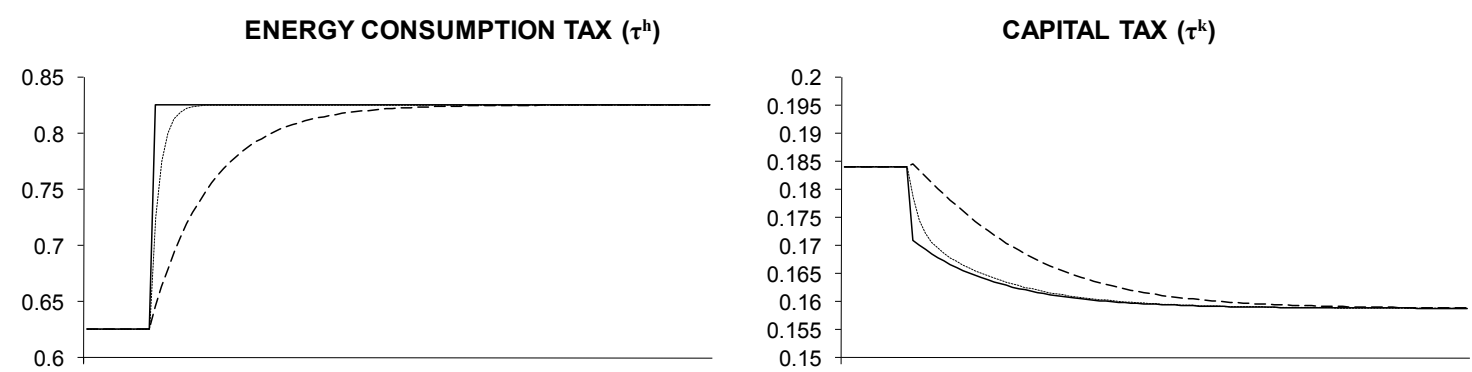

$-\rho=0 \quad-\rho=0.5 \quad--\rho=0.9$

$-\rho=0 \quad-\rho=0.5 \quad--\rho=0.9$

CONSUMPTION (c)
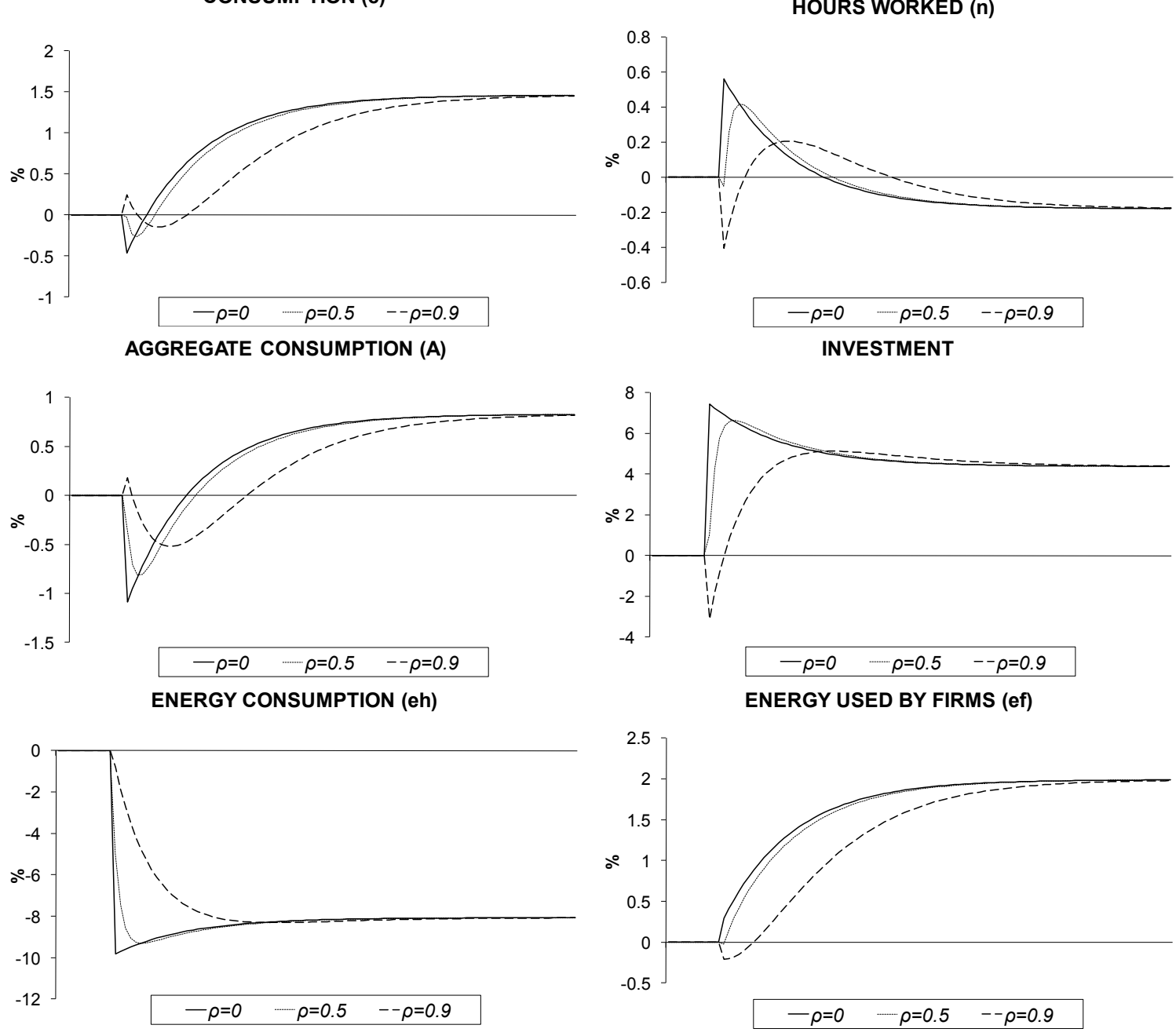
Figure 4.- Energy used by firms' tax. Deviations from the initial steady state (except taxes). Time period is one year.
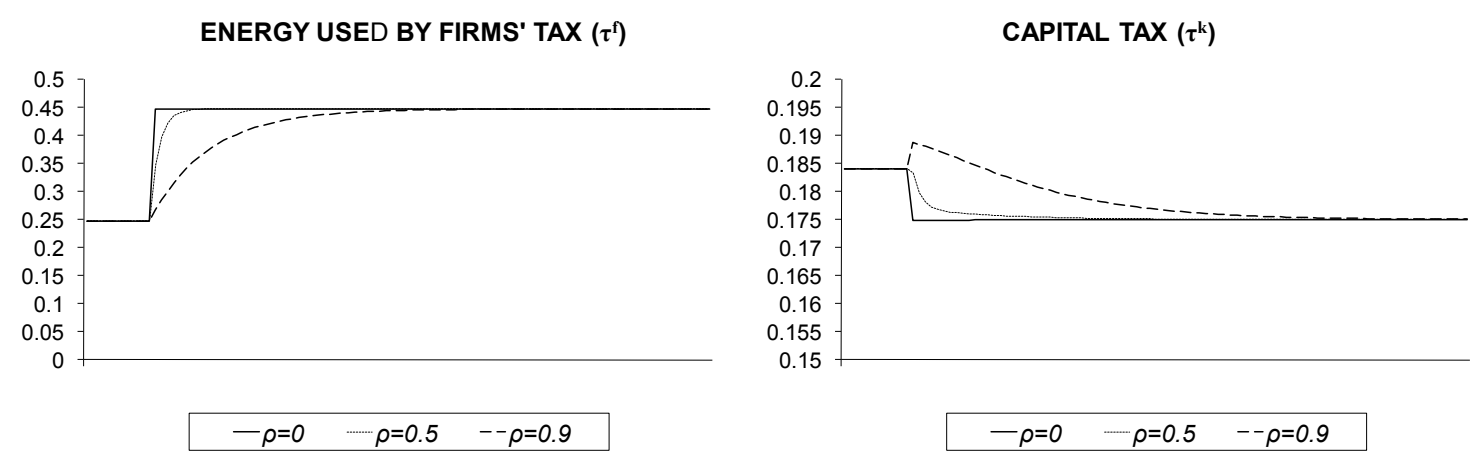

CONSUMPTION (c)
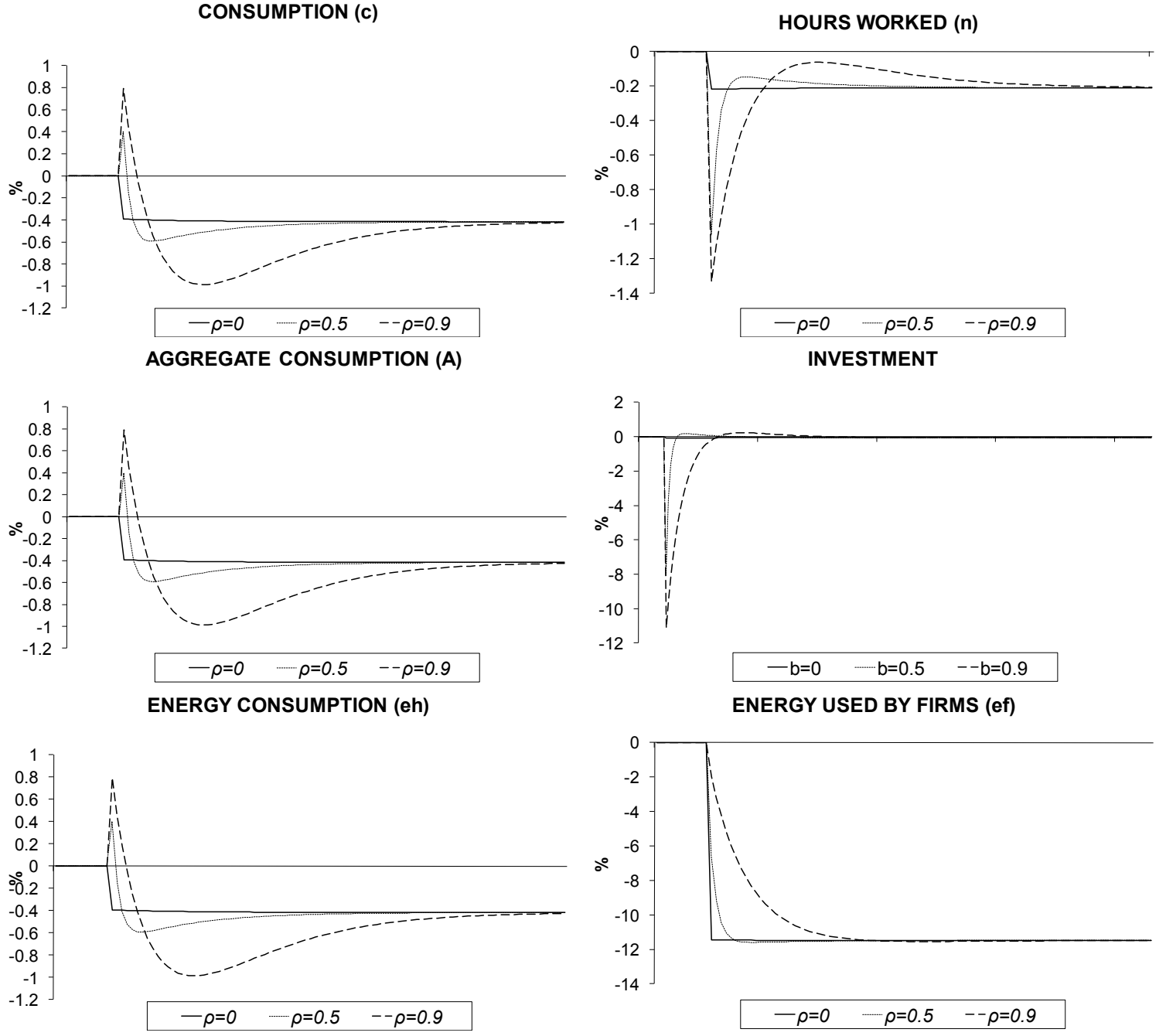